\title{
Development of a web-based register for the Dutch national study on biologicals in juvenile idiopathic arthritis: http://www.abc-register.nl
}

\author{
FHM Prince ${ }^{* 1}$, IS Ferket ${ }^{1}$, SSM Kamphuis ${ }^{1}$, W Armbrust ${ }^{2}$, R Ten Cate ${ }^{3}$, \\ EPAH Hoppenreijs ${ }^{4}$, Y Koopman-Keemink ${ }^{5}$, MAJ van Rossum ${ }^{6}$, M van \\ Santen-Hoeufft ${ }^{7}, M$ Twilt $^{1}$ and LWA van Suijlekom-Smit ${ }^{1}$
}

\author{
Address: ${ }^{1}$ Erasmus MC Sophia Children's Hospital, Rotterdam, Netherlands, ${ }^{2}$ UMCG Beatrix Children's Hospital, Groningen, Netherlands, \\ ${ }^{3}$ Leiden University Medical Centre, Leiden, Netherlands, ${ }^{4}$ Radboud University Nijmegen Medical Centre, Nijmegen, Netherlands, \\ ${ }^{5}$ Hagaziekenhuis Juliana Children's Hospital, Den Haag, Netherlands, ${ }^{6}$ AMC Emma Children's Hospital, Amsterdam, Netherlands and ${ }^{7}$ Academic \\ Hospital Maastricht, Maastricht, Netherlands \\ * Corresponding author
}

\author{
from I5th Paediatric Rheumatology European Society (PreS) Congress \\ London, UK. 14-17 September 2008 \\ Published: 15 September 2008 \\ Pediatric Rheumatology 2008, 6(Suppl I):PI53 doi:I0.I I86/I546-0096-6-SI-PI53
}

This abstract is available from: http://www.ped-rheum.com/content/6/SI/PI53

(c) 2008 Prince et al; licensee BioMed Central Ltd.

\section{Objectives}

Most clinical studies use paper case record forms (CRFs) to collect data. In the Dutch multicentre observational study on biologicals we encountered several disadvantages of using the paper CRFs. These are delay in data collection, lack of overview in collected data, and difficulties in obtaining up-to-date interim reports. Therefore we wanted to create a more effective method of data collection compared to CRFs on paper in a multicentre study.

\section{Methods}

We designed a web-based register with the intention to make it easy to use for participating physicians and at the same time accurate and up-to-date. Security demands were taken into account to secure the safety of the patient data.

\section{Results}

The web-based register was tested with data from 161 juvenile idiopathic arthritis patients from nine different centres. Internal validity was obtained and user-friendliness guaranteed. To secure the completeness of the data automatically generated email alerts were implemented into the web-based register. More transparency of data was achieved by including the option to automatically generate interim reports of data in the web-based register. The safety was tested and approved.

\section{Conclusion}

By digitalizing the CRF we achieved our aim to provide easy, rapid and safe access to the database and contributed to a new way of data collection. Although the web-based register was designed for the current multicentre observational study, this type of instrument can also be applied to other types of studies. We expect that especially collaborative study groups will find it an efficient tool to collect data. 